Metanalysis has suggested that baseline NLR is a promising predictor of ischemic stroke clinical outcomes. This study aims to evaluate the relationship between baseline NLR in patients with large vessel occlusion (LVO) and their imaging selection for endovascular treatment (ET).

Materials and Methods We reviewed our prospective stroke intervention database from Nov 2015 to June 2019 for patients that underwent ET for LVO with an admission NLR. Patients were excluded from the study if they received corticosteroids or had any history of infectious/systemic disease prior to the development of stroke symptoms. We studied patient demographics, vascular risk factors, NIHSS on admission, data from imaging (NCCT ASPECT, CTP $\mathrm{rCBF}<30 \%$, Tmax $>6$ s and mismatch ratio), and 90 days outcome measured by mRS. Statistical analysis was performed with SPSS version 17, univariate analysis was conducted between age, NLR, NIHSS, data from imaging and mRS using a correlation coefficient.

Results Seventy-eight met our inclusion criteria (mean age, 67 $\pm 19 ; 39 \%$ women, mean NIHSS, $17 \pm 6)$, 95\% $(n=74)$ were due to anterior circulation LVO while only $5 \%(n=4)$ were due to posterior circulation LVO occlusion. There was a significant positive correlation between NLR and $\mathrm{rCBF}<30 \%$ representing the volume of infarction core $(p=0.046)$, also there was a significant negative correlation between ASPECT score and $\mathrm{rCBF}<30 \% \quad(\mathrm{p}=0.035)$. No correlation was observed between NIHSS and ASPECT $(p=0.94)$ or NIHSS and $\mathrm{rCBF}<30 \% \quad(\mathrm{p}=0.83)$, however, there was a trend toward significance correlating NIHSS and Tmax $>6 \mathrm{~s}$ representing the volume of ischemic tissue $(p=0.09)$. Predictably, NLR was not correlating with 90 -days mRS $(p=0.703)$ as all patients in our cohort underwent ET, nevertheless, there was a significant correlation between age and 90-days mRS $(\mathrm{p}=0.001)$.

Conclusions NLR is an inexpensive and readily available biomarker that correlates with CTP predicted core infarction volume in LVO ischemic stroke. However, in CTP selected patients with relatively small core infarct volumes, NLR may not predict 90-day $\mathrm{mRS}$ as endovascular treatment salvages ischemic tissue, minimizes final infarct volume, and suggests follow-up NLR may be more valuable predictor of clinical outcome.

Disclosures M. Aly: None. R. Abdalla: None. M. Hurley: None. A. Shaibani: None. S. Ansari: None.

\section{E-076 OUTCOMES OF LARGE VESSEL OCCLUSION THROMBECTOMY IN PATIENTS WITH CT PERFUSION DEFINED LARGE CORE STROKE}

${ }^{1} \mathrm{~A}$ Aghaebrahim*, ${ }^{2} \mathrm{~S}$ Desai, ${ }^{1} \mathrm{~A}$ Monteiro, 'M Granja, ${ }^{1} \mathrm{G}$ Agnoletto, ${ }^{1} \mathrm{G}$ Cortez, ${ }^{1} \mathrm{D}$ Gonsales, ${ }^{3} \mathrm{C}$ Legault, ${ }^{4} \mathrm{C}$ Powers, ${ }^{2} \mathrm{~A}$ Jadhav, ${ }^{1} \mathrm{E}$ Sauvageau, ${ }^{3} \mathrm{G}$ Albers, ${ }^{2} \mathrm{~T}$ Jovin, ${ }^{1} \mathrm{R}$ Hanel. ${ }^{1}$ Neurosurgery, Baptist Health System- Jacksonville, Jacksonville, $F L ;{ }^{2}$ Department of Neurology, University of Pittsburgh Medical Center, Pittsburgh, PA; ${ }^{3}$ Department of Neurology, Stanford University, Palo Alto, CA; ${ }^{4}$ Neurosurgery, The Ohio State University, Columbus, $\mathrm{OH}$

\subsection{6/neurintsurg-2020-SNIS. 110}

Introduction The benefit of endovascular thrombectomy (ET) is well established in patients with small anterior circulation infarctions and large penumbra. However, this benefit is not proven in patients with a baseline large core infarction. This subpopulation was excluded from major thrombectomy clinical trials. The purpose of this study was to report the outcome of patients with large baseline core based on CTP who underwent stroke thrombectomy at 4 large stroke centers.

Methods Prospectively collected large vessel occlusion databases were queried to identify patients with large baseline infarct cores (CBF greater than $30 \% \geq 50 \mathrm{~mL}$; based on Computed Tomography Perfusion [CTP] processed by RAPID Software [iSchemaView]). All patients treated with thrombectomy were included in the study. Modified Rankin Scale (mRS) was used for evaluation of clinical outcomes at baseline and 90 days. Demographic information, baseline clinical data, radiological features (infarct core size, penumbra and collaterals) and follow-up were collected.

Results A total of 75 patients were included in the study. Mean age was $65 \pm 14.9$ years and $45.3 \%$ were male. Median infarct core was $75.5 \mathrm{~mL}$ (IQR 39) and median ASPECTS was 7 (range $3-10)$. Close to half $(50.7 \%)$ of patients received IV tPa. Only $8.3 \%$ of patients had good collaterals. Mean time to groin puncture was $373 \pm 384$ minutes and $88 \%$ of patients achieved TICI $2 \mathrm{~b}$ or higher. Rates of good outcome (mRS 0-2) and acceptable outcome (mRS 0-3) were $28.4 \%$ and $35.5 \%$ respectively. Rate of Parenchymal Hematoma type 2 was $10.6 \%$. The rate of good outcome was significantly higher in patients treated $<6 \mathrm{~h}(44.2 \%$ vs. $17.4 \%, \mathrm{P}=0.023)$.

Conclusions Acute stroke thrombectomy may be beneficial in some patients with large core based on CTP especially those who present early $(<6$ hours from last seen well) and it should not be withhold solely based on the estimated core infarct volume on CTP.

Disclosures A. Aghaebrahim: None. S. Desai: None. A. Monteiro: None. M. Granja: None. G. Agnoletto: None. G. Cortez: None. D. Gonsales: None. C. Legault: None. C. Powers: None. A. Jadhav: None. E. Sauvageau: None. G. Albers: 5; C; CEO of RAPID Software (iSchema View). T. Jovin: None. R. Hanel: 2; C; Microvention, Codman, Stryker, Medtronic.

\section{E-077 PROTEIN EXPRESSION OF INTRA-ARTERIAL BLOOD DISTAL AND PROXIMAL TO THROMBUS DURING MECHANICAL THROMBECTOMY}

${ }^{1}$ B Maglinger*, 'J Frank, ${ }^{2} \mathrm{C}$ McLouth, ${ }^{1} \mathrm{~A}$ Trout, ${ }^{1} \mathrm{~J}$ Roberts, ${ }^{3} \mathrm{~S}$ Grupke, ${ }^{1} \mathrm{~J}$ Turchan-Cholewo, ${ }^{1} \mathrm{~A}$ Stowe, ${ }^{3} \mathrm{~J}$ Fraser, ${ }^{1} \mathrm{~K}$ Pennypacker. ${ }^{1}$ Department of Neurology, University of Kentucky, Lexington, $K Y_{;}{ }^{2}$ Department of Behavioral Science, University of Kentucky, Lexington, $K Y_{i}$ ${ }^{3}$ Department of Neurosurgery, University of Kentucky, Lexington, KY

10.1136/neurintsurg-2020-SNIS.111 